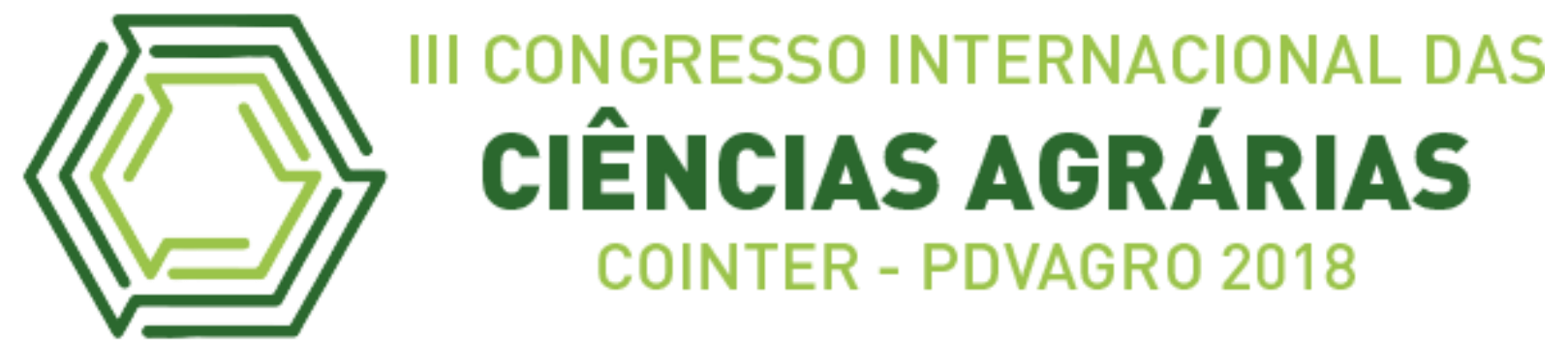

\title{
TEORES DE MACRONUTRIENTES (NPK) EM COENTRO COMERCIALIZADO EM FEIRAS LIVRES DE SÃO LUÍS / MA
}

\section{MACRONUTRIENT CONTENTS (NPK) IN COENTRO MARKETED IN FREE FAIRS OF SÃO LUÍS / MA}

\author{
Apresentação: Pôster \\ José de Arruda Barbosa ${ }^{1}$; Jonathan dos Santos Viana ${ }^{2}$; Thayane Leonel Alves ${ }^{3}$; Luiz \\ Fabiano Palaretti ${ }^{4}$; Maria do Socorro Nahuz Lourenço ${ }^{5}$ \\ DOI: https://doi.org/10.31692/2526-7701.IIICOINTERPDVAGRO.2018.00673
}

\section{Introdução}

A qualidade química é um dos principais parâmetros utilizado no controle dos alimentos visando principalmente à saúde humana. O acúmulo de nitrato em plantas alimentícias (hortaliças) e forrageiras é indesejável, pois quando ingerido, o nitrato pode ser reduzido a nitrito, entrar na corrente sanguínea e inativar a hemoglobina ou formar nitrosaminas, que são cancerígenas e mutagênicas (FAQUIN, 1994). Os macronutrientes são elementos de suma importância no bom desenvolvimento das plantas, pois fazem parte de vários processos bioquímicos e fisiológicos que favorecem seu crescimento.

O nitrogênio e o potássio são os nutrientes mais exigidos pelas culturas, necessitando de doses elevadas nas adubações e isso, particularmente com relação ao nitrogênio, tem trazido preocupação sob dois aspectos: pela contaminação de águas subterrâneas e dos mananciais, e pela elevação dos teores de nitrato $\left(\mathrm{NO}_{3}{ }^{-}\right)$nos alimentos, principalmente naqueles de consumo in natura, como as hortaliças e frutas. $\mathrm{O} \mathrm{NO}_{3}{ }^{-}$absorvido pelas raízes é reduzido a $\mathrm{NH}_{4}{ }^{+}$, sendo essa redução e o consequente acúmulo de nitrato nas plantas, afetados por diversos fatores, como os genéticos e ambientais, especialmente a intensidade luminosa que, quando for baixa, pode reduzir o acúmulo de nitrato e o sistema de cultivo (convencional, orgânico e hidropônico) (FAQUIN, 1994; MIYAZAWA, PAVAN, FRANCHINI, 2000).

\footnotetext{
${ }^{1}$ Mestrando em Agronomia (Ciência do Solo), UNESP Jaboticabal - SP. E-mail: josearruda777@gmail.com;

${ }^{2}$ Mestrando em Agronomia (Ciência do Solo), UNESP Jaboticabal - SP. E-mail: jonathan santu@hotmail.com;

${ }^{3}$ Mestranda em Agronomia (Ciência do Solo), UNESP Jaboticabal - SP. E-mail: thayaneleonel@hotmail.com;

4 Professor Doutor do Departamento de Engenharia Rural, UNESP Jaboticabal - SP. E-mail: ifpalaretti@fcav.unesp.br;

5 Professora Doutora da Universidade Estadual do Maranhão, Câmpus São Luís - MA. E-mail: snahuz@hotmail.com;
} 
Cerca de $90 \%$ do $\mathrm{N}$ total da planta está na forma orgânica, desempenhando as funções como componente estrutural de macromoléculas e constituintes de enzimas. Os aminoácidos livres dão origem a outros aminoácidos, às proteínas, às enzimas e coenzimas; são percussores de hormônios vegetais triptofano - AIA e metionina de etileno. Os núcleos porfirínicos formam a clorofila e os citocromos. As bases nitrogenadas são componentes de nucleotídeos e esses dos ácidos nucléicos - DNA, RNA, ATP e coenzimas como NAP e FAD (FAQUIN, 2005).

O potássio é o elemento que as olerícolas costumam necessitar de maior disponibilidade no solo, em relação às demais. Este elemento no solo aparece na forma de cátion potássio $\left(\mathrm{K}^{+}\right)$, sendo esta forma absorvida pelas raízes das hortaliças. Como o potássio é um íon monovalente ao competir com elevadas concentrações de cátion divalentes como o cálcio $\left(\mathrm{Ca}^{+2}\right)$ e o magnésio $\left(\mathrm{Mg}^{+2}\right)$ sofre inibição competitiva, ou seja, compete em desvantagem pelo mesmo sítio de absorção. Entretanto, baixas concentrações de $\mathrm{Ca}^{+2}$ contribuem para a sua absorção. (GLIESSMAN, 2000)

O fósforo é essencial para o crescimento das plantas e nenhum outro nutriente pode substituí-lo. A planta precisa de fósforo para completar seu ciclo normal de produção. As plantas absorvem a maior parte de seu fósforo como íon fosfato diácido $\left(\mathrm{H}_{2} \mathrm{PO}_{4}{ }^{-}\right)$. Pequenas quantidades do íon fosfato monoácido $\left(\mathrm{HPO}_{4}{ }^{-2}\right)$ são também absorvidas. Outras formas de fósforo podem ser utilizadas, mas em quantidades muito menores que os ortofosfatos. (FILGUEIRA, 1982).

Este trabalho foi realizado com o objetivo de identificar as principais hortaliças folhosas comercializadas em feiras livres de São Luís, e determinar a quantidade dos teores de macronutrientes (NPK) presentes em uma hortaliças mais consumida na região.

\section{Metodologia}

O experimento foi desenvolvido no Laboratório de Nutrição Mineral de Plantas, do Centro de Ciências Agrárias/CCA da Universidade Estadual do Maranhão/UEMA no período de agosto de 2013 a agosto de 2014.

Por meio da aplicação de questionários a consumidores em 5 feiras livres da cidade de São Luís/MA foram selecionadas 6 hortaliças folhosas de maior consumo e preferência. Foi adquirida uma amostra de uma das seis hortaliças mais comercializadas em cinco pontos comerciais de São Luís. As amostras foram transportadas para o Laboratório de Nutrição Mineral de Plantas, do Centro de Ciências Agrárias/CCA da Universidade Estadual do 
Maranhão/UEMA. As etapas de pré-tratamento, identificação e acondicionamento das amostras foram feitas de acordo com o Manual de Análises Químicas de Solos, Plantas e fertilizantes (EMBRAPA, 1999).

As amostras foram acondicionadas em sacos PVC transparentes de 100g, com pequenas perfurações sendo, posteriormente, armazenadas em refrigerador até o momento das análises. As amostras foram identificadas e em seguida seguiram para a etapa da descontaminação, onde além da lavagem inicial foi realizada uma lavagem com solução de ácido clorídrico a 3\% com posterior enxágue com água destilada. A descontaminação foi feita para retirar os possíveis resíduos decorrentes de adubação foliar com produtos contendo zinco, molibdênio e boro. $\mathrm{O}$ material vegetal amostrado foi submetido à secagem em estufa com temperatura controlada $\left(65-70^{\circ} \mathrm{C}\right)$, até peso constante. A moagem foi realizada em moinho de facas de aço inoxidável, tipo Willey, reduzindo as amostras em um pó fino (peneira de 20 a 40 mesh), facilitando a sua manipulação e assegurando a homogeneização.

Todas as análises químicas seguiram o descrito no Manual de Análises Químicas de Solos, Plantas e fertilizantes (EMBRAPA, 1999). A maioria das técnicas de análises químicas para tecido vegetal requer amostra líquida nas quais os elementos químicos são dissolvidos em soluções de ácidos ou álcalis e determinados por métodos apropriados.

Os macronutrientes foram submetidos à digestão úmida utilizando tubo digestor ou balão de Kjeldahl. Para a determinação de nitrogênio, as amostras foram submetidas à digestão sulfúrico/peróxido de hidrogênio $\left(\mathrm{H}_{2} \mathrm{SO}_{4} / \mathrm{H}_{2} \mathrm{O}_{2}\right)$, enquanto que para a determinação do teor de fósforo e potássio, as amostras foram submetidas à digestão nitro-perclórica $\left(\mathrm{HNO}_{3}+\mathrm{HClO}_{4}\right)$ na proporção de 3:1. O teor de nitrogênio foi determinado por titulometria com solução de ácido sulfúrico $0,05 \mathrm{~N}$ previamente padronizada, o teor de fósforo por espectrofotometria UV-VIS, utilizando um espectofotômetro Modelo SP-22, Marca Biospectro, e o teor de potássio foi determinado por fotometria de chama, utilizando um aparelho Modelo DM-61, Marca Digimed.

O delineamento experimental adotado foi o inteiramente casualizado (DIC), utilizandose 6 hortaliças de maior preferência e consumo, coletadas em 5 feiras livres (tratamentos) com 4 repetições. Os resultados obtidos foram submetidos à análise de variância utilizando-se o Programa Assistat versão 7.0, sendo que os efeitos de tratamentos (feiras) que apresentaram diferença significativa $(\mathrm{P}<0,01)$ as médias foram comparadas por meio da aplicação do Teste de Tukey $5 \%$ de probabilidade. 


\section{Resultados e Discussões}

A identificação das seis hortaliças folhosas de maior preferência e consumo na cidade de São Luís (MA) foi feita após a compilação dos resultados obtidos na aplicação dos questionários. A representação esquemática dos mesmos está apresentada na Figura 1.

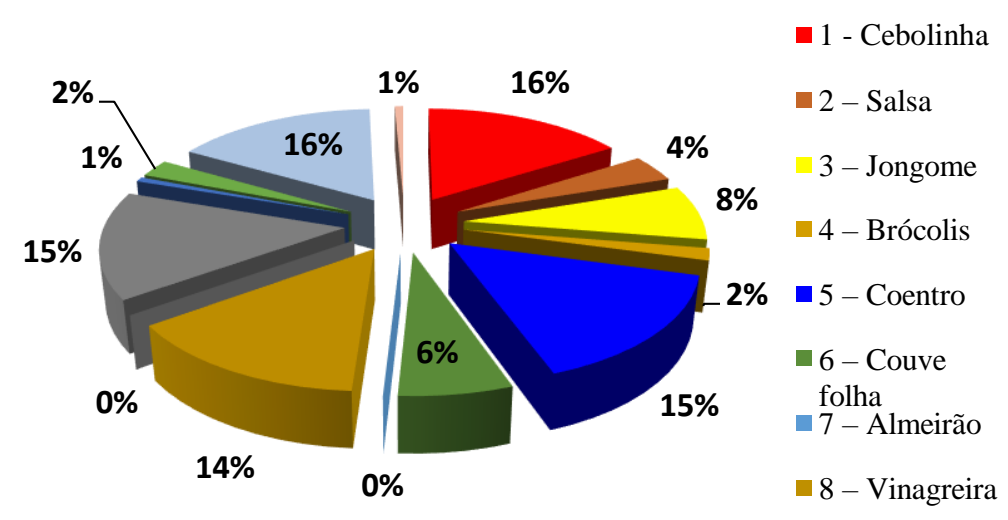

Figura 1. Representação esquemática da preferência e consumo de hortaliças folhosas na cidade de São Luís MA (VIANA et.al, 2014).

Considerando o universo de quatorze tipos de hortaliças, verificou-se que as seis hortaliças mais consumidas em São Luís - MA são: alface (16\%), cebolinha (16\%), coentro $(15 \%)$, repolho $(15 \%)$, vinagreira (14\%) e joao gomes (8\%). Com esse resultado, foi escolhido a hortaliça: coentro, para o estudo. Na Tabela 1 estão apresentadas as médias dos teores de $\mathrm{N}$ total, P e K nas amostras de plantas de coentro obtidas em diferentes pontos comerciais de São Luís - MA.

Tabela 1. Médias obtidas pela análise da variância em amostras de coentro coletadas em diferentes pontos comerciais de São Luís - MA, na avaliação dos teores de N total, P e K. São Luís-MA (2014).

\begin{tabular}{|c|c|c|c|}
\hline Feiras & $\mathrm{N}$ & $\mathrm{P}$ & $\mathrm{K}$ \\
\hline \multicolumn{4}{|c|}{--------------------------------g/Kg-1----------------------------- } \\
\hline Praia Grande & $36,50 \mathrm{a}$ & $7,11 \mathrm{bc}$ & $45,25 \mathrm{c}$ \\
\hline Pingão & $34,79 \mathrm{a}$ & $7,43 \mathrm{ab}$ & $59,12 \mathrm{~b}$ \\
\hline Cohab & $37,69 \mathrm{a}$ & $6,64 \mathrm{~cd}$ & $46,12 \mathrm{c}$ \\
\hline João Paulo & $29,12 \mathrm{a}$ & $7,87 \mathrm{a}$ & $78,62 \mathrm{a}$ \\
\hline Angelim & $31,06 \mathrm{a}$ & $6,19 \mathrm{~d}$ & $56,25 \mathrm{~b}$ \\
\hline DMS & 10,01 & 0,65 & 9,14 \\
\hline $\mathrm{DP}$ & 3,249 & 0,587 & 12,073 \\
\hline $\mathrm{CV} \%$ & 13,55 & 4,23 & 7,33 \\
\hline
\end{tabular}

Médias seguidas de letras minúsculas iguais na mesma coluna não diferem estatisticamente entre si, segundo teste de Tukey a $5 \%$ de probabilidade. DMS = Diferença mínima significativa. $\mathrm{DP}=$ Desvio padrão. $\mathrm{CV} \%$ Coeficiente de variação. 
Os valores encontrados de nitrogênio nas amostras estão variando entre 29,125 a 36,5 g $\mathrm{Kg}^{-1}$ de material seco. $\mathrm{O}$ fornecimento de doses adequadas de nitrogênio favorece o crescimento vegetativo, expande a área fotossinteticamente ativa e eleva o potencial produtivo da cultura. Todas as espécies são beneficiadas, porém as hortaliças herbáceas são aquelas que apresentam efeito direto na produtividade, já que o produto é constituído por folhas, hastes tenras e inflorescência (FILGUEIRAS, 2000). Segundo Oliveira et al. (2003), o rendimento de massa verde de coentro aumentou de forma linear com o incremento das doses de $\mathrm{N}$, ocorrendo aumento na ordem de $0,0256 \mathrm{~kg} \mathrm{~m}^{-2}$ a cada quilograma de $\mathrm{N} \mathrm{ha}^{-1}$ adicionado ao solo. $\mathrm{O}$ rendimento máximo de massa verde foi de $5,4 \mathrm{~kg} \mathrm{~m}^{-2}$, obtido na dose de $80 \mathrm{~kg} \mathrm{ha}^{-1}$.

Neste trabalho o acúmulo de fósforo variou de 6,195 a 7,870 $\mathrm{g} \mathrm{Kg}^{-1}$ de material, sendo que não ocorreram diferenças entre as amostras das feiras do João Paulo e Pingão, mas essas duas diferiram estatisticamente das outras feiras analisadas. No trabalho desenvolvido por Granjeiro et al., (2011) o fósforo foi o nutriente de menor acúmulo pelo coentro, com o máximo de 3,47 mg planta ${ }^{-1}$, atingido aos 40 dias. Segundo Coutinho, Natale e Souza, (1993), as quantidades de fósforo retiradas do solo pelas hortaliças são geralmente baixas, principalmente quando comparadas com as de nitrogênio e potássio. Entretanto, apesar dessa aparente baixa exigência, os teores desse nutriente na solução do solo, bem como a velocidade do seu restabelecimento, não são suficientes para atender as necessidades das culturas. Como consequência, nas adubações, é o fósforo que entra em maiores proporções.

O potássio foi o nutriente encontrado em maior quantidade nas análises realizadas variando entre 45,25 a 59,12 $\mathrm{g} \mathrm{Kg}^{-1}$ de material, esses valores corroboram com o trabalho desenvolvido por Granjeiro et.al (2011) no qual o potássio foi o nutriente mais absorvido pelo coentro Verdão, com acúmulo máximo de $25,43 \mathrm{mg} \mathrm{planta}^{-1}$. O potássio, embora não faça parte de nenhum composto orgânico, desempenha importantes funções na planta, como na fotossíntese, ativação enzimática, síntese de proteínas, transporte de carboidratos, entre outros, e é, portanto, fundamental ao crescimento e produção da planta.

\section{Conclusões}

As hortaliças folhosas selecionadas têm influencia diretamente sob o aspecto regional de São Luís, o que foi percebido pela preferência de consumo por vinagreira (14\%) e joao gomes $(8 \%)$, além de alface (16\%), cebolinha (16\%), coentro (15\%) e repolho (15\%).

Devido a variação dos teores de $\mathrm{P}$ e $\mathrm{K}$ das amostras entre as feiras, demostram o uso de 
forma indiscriminada (excesso ou deficiência) de macronutrientes por produtores de folhosas, isto tem provocado efeito direto nesse mercado. Logo, a adubação correta é de suma importância, proporcionando aumento da produtividade e da qualidade do produto.

\section{Referências}

COUTINHO, E. L. M.; NATALE, W.; SOUZA, E. C. A. Adubos e corretivos: aspectos particulares na olericultura. In: FERREIRA, M. E.; CASTELLANE, P. D.; CRUZ, M. C. P. (Coords.). Nutrição e adubação de hortaliças. Jaboticabal: Faculdade de Ciências Agrárias e Veterinárias, 1993. p. 85-140.

EMBRAPA SOLOS, EMBRAPA INFORMÁTICA AGROPECUÁRIA. Manual de Análises Químicas de Solos, Plantas e Fertilizantes. Rio de Janeiro: [s.n.], 1999.

FAQUIM, V. Nutrição mineral de plantas. Lavras: FAEPE, 1994.

FAQUIN, V. Nutrição mineral de plantas. Lavras: UFLA / FAEPE, 2005. p.: il. - Curso de Pós-Graduação "Lato Sensu” (Especialização) a Distância: Solos e Meio Ambiente. 186f. data de 2005.

FILGUEIRA, F. A. R. Manual de olericultura: cultura e comercialização de hortaliças. 2. ed. São Paulo: Agronômica Ceres, 1982. v. 1.

FILGUEIRA, F. A. R. Novo Manual de Olericultura: Agrotecnologia moderna na produção e comercialização de hortaliças. Viçosa: UFV, 2000. 402p.

GLIESSMAN, S. R. Agroecologia: processos ecológicos em agricultura sustentável. Porto Alegre: Editora da Universidade - UFRGS, 2000.

GRANGEIRO, L. C.; OLIVEIRA, F. C. L.; NEGREIROS, M. Z.; MARROCOS, S. de T. P.; LUCENA, R. R. M., OLIVEIRA, R. A. Crescimento e acúmulo de nutrientes em coentro e rúcula. Revista Brasileira de Ciências Agrárias, vol. 6, n. 1, p. 11-16, 2011.

MIYAZAWA, M.; PAVAN, M.A.; FRANCHINI, J.C. Resíduos vegetais: Influência na química de solos ácidos. In: SIMPÓSIO SOBRE FERTILIDADE DO SOLO E NUTRIÇÃO DE PLANTAS NO SISTEMA DE PLANTIO DIRETO, Ponta Grossa, 2000. Anais. Ponta Grossa, Associação dos Engenheiros Agrônomos dos Campos Gerais, 2000. p.82-94.

OLIVEIRA, A.P.; PAIVA SOBRINHO, S.; BARBOSA, J.K.A.; RAMALHO, C.I.; OLIVEIRA, A.L.P. Rendimento de coentro cultivado com doses crescentes de N. Horticultura Brasileira, Brasília, v. 21, n. 1, p. 81-83, março 2003. 